\title{
Porous nitrogen/halogen dual-doped nanocarbons derived from imidazolium functionalized cationic metal-organic frameworks for highly efficient oxygen reduction reaction
}

\author{
Qiao $\mathrm{Wu}^{1,2}$, Jun Liang ${ }^{1}$, Jun-Dong $\mathrm{Yi}^{1}$, Peng-Chao Shi ${ }^{1}$, Yuan-Biao Huang ${ }^{1 *}$ and Rong Cao ${ }^{1,3^{*}}$
}

\begin{abstract}
Heteroatom-doped carbon materials as alternative catalysts for oxygen reduction reaction (ORR) have drawn increasing attention due to their tunable chemical and electronic structures for achieving high activity and stability. However, there still remains a great challenge to fabricate porous heteroatoms dual-doped carbons with uniformly doping in a facile and controllable way. Herein, imidazole/imidazolium-functionalized metal-organic frameworks (MOFs) are employed as precursors and templates to achieve porous nitrogen and halogen dual-doped nanocarbons. Among these carbon materials, the as-prepared nitrogen/bromine dual-doped catalyst BrNC-800 exhibits the best ORR performance with a positive half-wave potential at $0.80 \mathrm{~V}$ (vs. RHE) in $0.1 \mathrm{~mol} \mathrm{~L}^{-1} \mathrm{KOH}$, which is comparable to the benchmark commercial $20 \mathrm{wt} \% \mathrm{Pt} / \mathrm{C}$ catalyst. BrNC-800 shows excellent long term stability and methanol tolerance. This work provides a facile approach to fabricate highly efficient heteroatoms dual-doped carbon catalysts for energy conversion.
\end{abstract}

Keywords: cationic metal-organic framework, imidazolium, nitrogen/halogen dual-doped, nanocarbon catalysts, oxygen reduction reaction

\section{INTRODUCTION}

Oxygen reduction reaction (ORR) is one of the most important cathodic reaction in the anion-exchange membrane based alkaline fuel cells (AFCs) [1,2]. However, high loading of expensive and scarce Pt-based catalysts is employed to overcome the intrinsically sluggish kinetics of ORR, which leads to high cost and hinders its large-scale application [3-8]. Various approaches have been conducted to lower Pt content or avoid the use of Pt by fabricating Pt-based alloys and non-noble-metal catalysts (NNMCs) [9-20]. Among these NNMCs, carbon-based materials doped with hetero-atoms, such as N [21-23], B [24,25], P [26], S [27], halogen $[28,29]$ have been developed because their different electronegativity can affect the charge distribution of adjacent carbon atoms and thus create the active sites and enhance the oxygen reduction activity $[12,21,30]$. Although the porous carbons with multiple heteroatom co-doping, such as $\mathrm{S} / \mathrm{N}$ [31-34], $\mathrm{P} / \mathrm{N}$ [35], N/ F [36,37] appear to be candidates for ORR catalysts $[32,38,39]$, the fabrication of porous nitrogen and halogen dual-doped carbon catalysts with uniform doping and high ORR activity is rarely reported.

Traditional methods of doping halogen into carbon usually require large amount of halide salt under harsh acid conditions or the direct use of highly toxic halogen gases $[28,29,37]$. Imidazolium contains abundant nitrogen and halogen atoms, which can be employed as precursors for preparing nitrogen and halogen dualdoped carbons [40]. However, the direct use of imidazolium for carbonization suffers low carbonization yield $[41,42]$. High yield of functional carbon materials could be obtained by exploiting porous precursors containing imidazolium halide [43-45]. Metal-organic

\footnotetext{
${ }^{1}$ State Key Laboratory of Structural Chemistry, Fujian Institute of Research on the Structure of Matter, Chinese Academy of Sciences, Fuzhou 350002, China

${ }^{2}$ College of Chemistry and Materials Science, Fujian Normal University, Fuzhou 350007, China

${ }^{3}$ University of Chinese Academy of Sciences, Beijing 100049, China

* Corresponding authors (emails: ybhuang@fjirsm.ac.cn (Huang YB); rcao@fjirsm.ac.cn (Cao R))
} 
frameworks (MOFs) constructed by organic linkers and metal ions are promising precursors and/or templates to endow the obtained porous carbon materials with uniform heteroatom-doping and large surface areas [46-57]. However, up to now, there is only one example using imidazolium/MOF composites as precursors to obtain N/B dual doped carbon materials [48]. Furthermore, it is difficult to control the synthesis and distribution of heteroatoms in the carbon materials when imidazolium/MOF composites are used as precursors. On the contrary, the nitrogen and various halogen atoms can be introduced quantitatively when imidazolium-based linkers are used to construct MOF precursor. It would be easy to make nitrogen and halogen atoms be uniformly doped into the porous carbon materials for ORR.

Herein, nanoscale imidazolium-functionalized $\mathrm{Zr}$ MOFs were employed as precursors and carbonized to give porous $\mathrm{N}$ and halogen dual-doped nanocarbons (Scheme 1). For comparison, the $\mathrm{N}$-doped nanocarbon was also prepared from the nanoscale imidazolefunctionalized $\mathrm{Zr}-\mathrm{MOF}$. Among these nanocarbons, the $\mathrm{N} / \mathrm{Br}$ dual-doped BrNC-800 with high porosity and surface area $\left(1,165 \mathrm{~m}^{2} \mathrm{~g}^{-1}\right)$ exhibited an excellent performance with a positive half-wave potential of $0.80 \mathrm{~V}$ ( $v$ s. RHE) and a high diffusion-limited current density of $6.00 \mathrm{~mA} \mathrm{~cm}^{-2}$ at $0.2 \mathrm{~V}$ in alkaline media. Furthermore, compared with the benchmark commercial $\mathrm{Pt} / \mathrm{C}$ (Alfa Aesar, $20 \mathrm{wt} \%$ ), BrNC-800 showed excellent long term stability, methanol tolerance and high catalytic efficiency (four-electron path selectivity) in ORR.

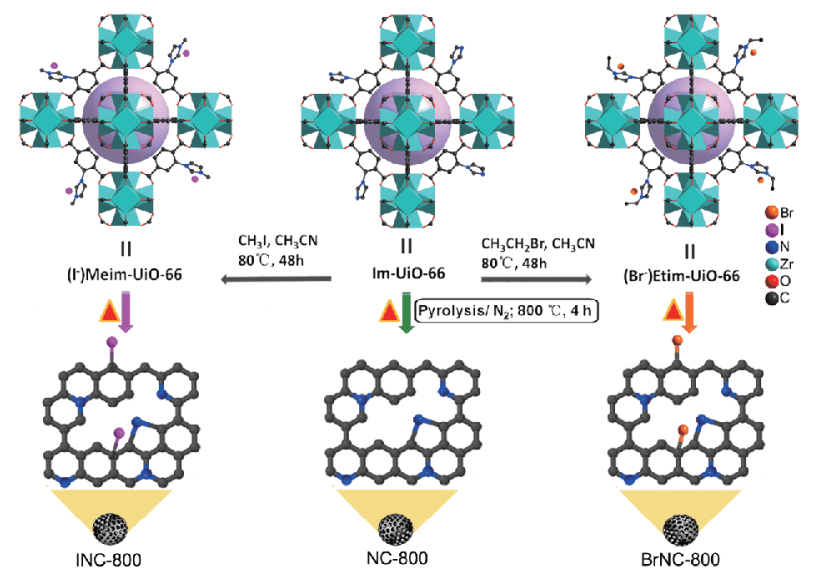

Scheme 1 Preparation of nanoscale Im-UiO-66, ( $\left.\mathrm{I}^{-}\right)$Meim-UiO-66 and $\left(\mathrm{Br}^{-}\right)$Etim-UiO-66 via post-synthetic ionization (PSI) strategy and their conversion to heteroatoms doped nanocarbons, which are denoted as NC-800, INC-800 and BrNC-800 via carbonization at $800^{\circ} \mathrm{C}$ and acid etching treatment. Lavender sphere represents the pore cavity.

\section{EXPERIMENTAL SECTION}

\section{General experiments}

2-(Imidazol-1-yl)terephthalic acid $\left(\mathrm{Im}-\mathrm{H}_{2} \mathrm{BDC} \cdot \mathrm{HCl} \cdot \mathrm{H}_{2} \mathrm{O}\right)$ was prepared according to previous literature [58]. Zirconium chloride (Strem Chemicals, Incorporated, 99.95\%), acetonitrile (AR) and bromoethane (AR) were acquired from Aladdin. Ethanol, acetone and ether were purchased from Sinopharm Chemical Reagent Co., Ltd, Hydrofluoric acid (General Reagent, 40\%), and commercial Pt/C (Alfa Aesar, $20 \mathrm{wt} \%$ metal) were purchased from the commercial corporations.

\section{Synthesis of $\left(\mathrm{Br}^{-}\right)$Etim-UiO-66}

Imidazole functionalized $\mathrm{UiO}-66 \quad(\mathrm{Im}-\mathrm{UiO}-66)$ and imidazolium iodide functionalized UiO-66 $\left(\left(\mathrm{I}^{-}\right)\right.$Meim-UiO-66) nanoparticles were synthesized as our previous report [58]. ( $\left.\mathrm{Br}^{-}\right)$Etim-UiO-66 was synthesized in a similar way as that of $\left(\mathrm{I}^{-}\right) \mathrm{Meim}-\mathrm{UiO}-66$, but iodomethane was replaced by bromoethane. $\mathrm{A}^{\mathrm{CH}_{3} \mathrm{CN}}$ $(15 \mathrm{~mL})$ suspension of Im-UiO-66 nanoparticles $(0.25 \mathrm{~g})$ and bromoethane $(0.8 \mathrm{~mL})$ was heated at $80^{\circ} \mathrm{C}$ for $48 \mathrm{~h}$ under $\mathrm{N}_{2}$ atmosphere. The product was collected by centrifugation and washed with ethanol $(10 \mathrm{~mL} \times 2)$, acetone $(10 \mathrm{~mL} \times 2)$ and ether $(10 \mathrm{~mL} \times 2)$ to generate $\left(\mathrm{Br}^{-}\right)$Etim-UiO-66 as white solid powder after drying at $70^{\circ} \mathrm{C}$ under vacuum for $12 \mathrm{~h}$. Elemental analysis for $\left(\mathrm{Br}^{-}\right)$Etim-UiO-66 (found): C, 27.43; N, 4.65; H, 3.6; Zr, 20.37 (\%). Infrared bands $\left(\mathrm{KBr}, v_{\max }, \mathrm{cm}^{-1}\right): 3,418(\mathrm{w})$, 3,146 (w), 3,090 (w), 2,986 (w), 1,717 (s), 1,597 (s), 1,503 (s), 1,387 (m), 1,115 (s), $772(\mathrm{~s}), 654(\mathrm{~s})$.

\section{Preparation of porous N/halogen dual-doped nanocarbons} (I-)Meim-UiO-66 or ( $\left.\mathrm{Br}^{-}\right)$Etim-UiO-66 (200 mg) was activated at $120^{\circ} \mathrm{C}$ under vacuum for $6 \mathrm{~h}$ before the MOF powder was placed into a quartz tube and annealed at $800^{\circ} \mathrm{C}$ for $4 \mathrm{~h}$ in flowing nitrogen atmosphere $(0.1 \mathrm{MPa}$, $50 \mathrm{sccm}$ ) to give INC-800 or BrNC-800, respectively. The samples collected from the quartz tube were etched with $5 \% \mathrm{HF}$ at room temperature to remove the residual zirconium species, followed by washing with distilled water and ethanol, and dried at $70^{\circ} \mathrm{C}$ for $12 \mathrm{~h}$.

\section{Preparation of NC-800 material}

NC-800 was prepared by the same process as that of BrNC-800 except that Im-UiO-66 (200 mg) was used as precursor.

\section{Characterizations}

$\mathrm{N}_{2}$ sorption isotherms for MOFs and the derived carbon 
materials were measured by using a Micrometrics ASAP 2020 instrument at $77 \mathrm{~K}$. Before the measurement, the samples were activated at $393 \mathrm{~K}$ in vacuum for $12 \mathrm{~h}$. Powder X-ray diffraction (PXRD) patterns were recorded on a Rigaku Dmax 2500 diffractometer equipped with $\mathrm{Cu}-\mathrm{Ka}$ radiation $(\lambda=1.54056 \AA)$ over the $2 \theta$ range of 4 $40^{\circ}$ for MOFs and $4-80^{\circ}$ for carbon materials with a scan speed of $3^{\circ} \mathrm{min}^{-1}$ at room temperature. Infrared (IR) spectra were recorded using $\mathrm{KBr}$ pellets on a PerkinElmer Spectrum in the range of $400-4,000 \mathrm{~cm}^{-1}$. Raman spectra of dried samples were obtained on Lab-RAM HR800 with excitation by an argon ion laser $(532 \mathrm{~nm})$. Elemental analyses of $\mathrm{C}, \mathrm{H}$, and $\mathrm{N}$ were carried out on an Elementar Vario EL III analyzer. ${ }^{1} \mathrm{H}$ NMR was performed at AVANCE III BrukerBiospin spectrometer, operating at $400 \mathrm{MHz} .12 \mathrm{mg} \mathrm{Zr}-\mathrm{MOF}$ samples was dissolved in a mixed solvent of $500 \mu \mathrm{L}$ DMSO- $\mathrm{d}_{6}$ and $30 \mu \mathrm{L} \mathrm{HF}$ for NMR analysis. The morphologies of MOFs were studied using a (JSM-6700F) scanning electron microscope (SEM) working at $10 \mathrm{kV}$. The transmission electron microscopy (TEM) and high resolution TEM (HRTEM) images were obtained on a FEI T20 instrument at an accelerating voltage of $200 \mathrm{kV}$. The energy dispersive $\mathrm{X}$ ray spectroscopy (EDS) of samples were performed with a Titan Cubed Themis G2 300 (FEI) operated at 200 kV. Xray photoelectron spectroscopy (XPS) measurements were performed on an ESCALAB 250Xi X-ray photoelectron spectrometer (Thermo Fisher) using an Al Ka source $(15 \mathrm{kV}, 10 \mathrm{~mA})$.

All electrochemical measurements were performed in IM6ex (Zahner, Germany) using three-electrode system at room temperature: $\mathrm{Pt}$ foil and an $\mathrm{Ag} / \mathrm{AgCl}$ electrode in saturated $\mathrm{KCl}$ solution were used as counter and reference electrodes, respectively, while glassy carbon electrode with a diameter of $5 \mathrm{~mm}$ coated with our carbons as the working electrode. For preparation of working electrodes, $5 \mathrm{mg}$ of the catalyst was dispersed in $1 \mathrm{~mL}$ of isopropanol and $40 \mu \mathrm{L}$ of Nafion binder solution ( $5 \mathrm{wt} \%$ ) under sonication for $1 \mathrm{~h}$ to form a homogeneous ink. Then $20 \mu \mathrm{L}$ of the catalyst ink was loaded onto a glass carbon electrode (GCE, loading amount: $0.49 \mathrm{mg} \mathrm{cm}^{-2}$ ). For comparison, $\mathrm{Pt} / \mathrm{C}$ (20 wt\% platinum) was conducted on the same electrochemical tests with a catalyst loading of $0.1 \mathrm{mg} \mathrm{cm}$. Before electrochemical measurements, pure nitrogen or oxygen gas was continuously purged into the electrolytic bath that was filled with $0.1 \mathrm{~mol} \mathrm{~L}^{-1}$ $\mathrm{KOH}$ solution. Rotating disk electrode (RDE) and rotating ring-disk electrode (RRDE) tests were performed with a speed of $5 \mathrm{mV} \mathrm{s}^{-1}$ at different rotation rates. The durability and methanol poisoning were tested with RDE in an $\mathrm{O}_{2}$ saturated $0.1 \mathrm{~mol} \mathrm{~L}^{-1} \mathrm{KOH}$ solution via a chronoamperometric method. All measured potentials were converted to reversible hydrogen electrode (RHE) scale using the following equation: $E_{\mathrm{RHE}}=E_{\mathrm{Ag} / \mathrm{AgCl}}+0.059$ $\mathrm{pH}+0.197 \mathrm{~V}$. Electron transfer numbers $(n)$ and kinetic current density $\left(J_{\mathrm{K}}\right)$ were calculated by the KouteckyLevich (K-L) equations:

$$
\begin{gathered}
\frac{1}{J}=\frac{1}{J_{\mathrm{L}}}+\frac{1}{J_{\mathrm{K}}}=\frac{1}{B \omega^{1 / 2}}+\frac{1}{J_{\mathrm{K}}} \\
B=0.2 n F C_{0} D_{0}^{2 / 3} v^{-1 / 6} \\
n=\frac{4 I_{\mathrm{d}}}{I_{\mathrm{d}}+I_{\mathrm{r}} / N}
\end{gathered}
$$

where $J, J_{\mathrm{L}}$ and $J_{\mathrm{K}}$ are the measured current density, diffusion limiting current and the kinetic-limiting current density, respectively. $\omega$ is angular velocity of the disk; $n$ is the number of electrons transferred in the reduction of one $\mathrm{O}_{2}$ molecule. $F$ is the Faraday constant $\left(96,485 \mathrm{C} \mathrm{mol}^{-1}\right) ; \quad C_{0}$ is the $\mathrm{O}_{2}$ concentration in $0.1 \mathrm{~mol} \mathrm{~L}^{-1} \mathrm{KOH}$ solution $\left(1.2 \times 10^{-6} \mathrm{~mol} \mathrm{~cm}^{-3}\right), D_{0}$ is the diffusion coefficient of $\mathrm{O}_{2}$ in $0.1 \mathrm{~mol} \mathrm{~L}^{-1} \mathrm{KOH}$ solution $\left(1.9 \times 10^{-5} \mathrm{~cm}^{2} \mathrm{~s}^{-1}\right)$, and $v$ is the kinetic viscosity of the solution $\left(0.01 \mathrm{~cm}^{2} \mathrm{~s}^{-1}\right) . B$ is calculated to be $0.144 \mathrm{~mA} \mathrm{~s}^{-1 / 2}$ at $A=0.19625 \mathrm{~cm}^{2}$ for a four-electron exchange reaction $(n=4) . I_{\mathrm{r}}$ is the ring current and $I_{\mathrm{d}}$ is the disk current, while $N$ refers to the collection efficiency (0.4) of the ring electrode. The constant 0.2 was adapted when the rotation speed is expressed in rpm.

RRDE measurements for the catalysts were conducted by the same method as for the RDE tests at 1,600 rpm. The disk electrode was scanned at a rate of $5 \mathrm{mV} \mathrm{s}^{-1}$ and the ring electrode potential was set to $0.5 \mathrm{~V} v s$. $\mathrm{Ag} / \mathrm{AgCl}$. The hydrogen peroxide yield $\left(\mathrm{H}_{2} \mathrm{O}_{2} \%\right)$ by the following equations:

$$
\mathrm{H}_{2} \mathrm{O}_{2}(\%)=\frac{200 I_{\mathrm{r}} / N}{I_{\mathrm{d}}+I_{\mathrm{r}} / N}
$$

where $I_{\mathrm{d}}$ is the disk current, $I_{\mathrm{r}}$ is the ring current and $N=0.4$ is the current collection efficiency of the Pt ring.

\section{RESULTS AND DISCUSSION}

The preparations of imidazole- and imidazolium functionalized MOFs and subsequent pyrolysis to porous $\mathrm{N}$-doped or $\mathrm{N} /$ halogen dual-doped nanocarbons under an $\mathrm{N}_{2}$ atmosphere are illustrated in Scheme 1. Im-UiO-66 (Scheme $\mathrm{S} 1$ ) and $\left(\mathrm{I}^{-}\right)$Meim-UiO-66 were synthesized as our previous report [58]. ( $\left.\mathrm{Br}^{-}\right)$Etim-UiO-66 was synthesized in a similar post-synthetic ionization (PSI) method to that of $\left(\mathrm{I}^{-}\right)$Meim-UiO-66, but bromoethane was used. As shown in Fig. S1a, PXRD patterns of Im-UiO-66, $\left(\mathrm{I}^{-}\right)$ 
Meim-UiO-66 and (Br $\left.{ }^{-}\right)$Etim-UiO-66 are consistent with those of UiO-66, indicating they have topologically isostructural frameworks. The successful formation of $\left(\mathrm{Br}^{-}\right)$Etim-UiO-66 was further confirmed by solid ${ }^{13} \mathrm{C}$ NMR, XPS and mass spectra (Figs S1, S2). Compared with the ${ }^{13} \mathrm{C}$ NMR (Fig. S1b) spectrum of Im-UiO-66, $\left(\mathrm{Br}^{-}\right)$Etim-UiO-66 showed two new peaks at around 40 and $13.2 \mathrm{ppm}$, ascribed to the methylene and methyl carbon of the ethyl groups. The existence of imidazolium and imidazole species in $\left(\mathrm{Br}^{-}\right)$Etim-UiO-66 was verified by XPS analysis (Fig. S1c). The binding energy of $\mathrm{N} 1 \mathrm{~s}$ at 401.6 and $400.0 \mathrm{eV}$ were ascribed to two different types of nitrogen atoms $\left(\mathrm{C}=\mathrm{N}^{+}-\mathrm{Et},-\mathrm{N}-\mathrm{BDC}\right)$ in the imidazolum of $\left(\mathrm{Br}^{-}\right)$Etim-UiO-66, while the binding energy at $398.6 \mathrm{eV}(\mathrm{N} \mathrm{1s}, \mathrm{C}=\mathrm{N})$ was assigned to the unionized imidazole moieties of the framework. ${ }^{1} \mathrm{H}$ NMR analyses indicated that ca. $63 \%$ and $80 \%$ of the imidazole groups were converted to imidazolium for $\left(\mathrm{I}^{-}\right) \mathrm{Meim}-\mathrm{UiO}-66$ and $\left(\mathrm{Br}^{-}\right)$Etim-UiO-66, respectively (Figs S3, S4). Thus, ca. $14.0 \mathrm{wt} \%$ of iodine and $10.6 \mathrm{wt} \%$ of bromine were successfully incorporated into $\left(\mathrm{I}^{-}\right) \mathrm{Meim}-\mathrm{UiO}-66$ and $\left(\mathrm{Br}^{-}\right)$Etim-UiO-66, respectively. Elemental analysis revealed that $\left(\mathrm{I}^{-}\right)$Meim-UiO-66 and $\left(\mathrm{Br}^{-}\right)$Etim-UiO-66 contain 4.93 and $4.65 \mathrm{wt} \%$ of $\mathrm{N}$ contents, respectively. Such high contents of $\mathrm{N}$ and halogen elements in these two MOFs were beneficial for the doping of heteroatoms into carbons, thereby increasing the active sites for ORR.

In addition, the synthesized Im-UiO-66, (I')MeimUiO-66 and $\left(\mathrm{Br}^{-}\right)$Etim-UiO-66 showed high BrunnerEmmet-Teller (BET) surface areas of 491, 282 and $287 \mathrm{~m}^{2} \mathrm{~g}^{-1}$, respectively (Fig. S1d and Table S1). It should be noted that the PSI method ensured that Im-UiO-66, $\left(\mathrm{I}^{-}\right)$Meim-UiO-66 and $\left(\mathrm{Br}^{-}\right)$Etim-UiO-66 nanoparticles have similar sizes of $20-30 \mathrm{~nm}$ (Fig. S5), which can be comparable to corresponding nanocarbons.

As shown in Scheme 1, the porous nitrogen/halogen dual-doped nanocarbons, denoted INC-800 and BrNC800 , were prepared by annealing $\left(\mathrm{I}^{-}\right) \mathrm{Meim}-\mathrm{UiO}-66$ or $\left(\mathrm{Br}^{-}\right)$Etim-UiO-66 at $800^{\circ} \mathrm{C}$ in nitrogen atmosphere and followed by acid etching to remove zirconium species. For comparison, nitrogen-doped nanocarbon NC-800 was also fabricated from Im-UiO-66 under the same conditions. As shown in Fig. 1a, these porous nanocarbons showed similar PXRD patterns with two broad peaks at around $24^{\circ}$ and $44^{\circ}$, corresponding to the characteristic peaks of graphitic carbon (002) and (101) $[59,60]$. No other phase peak was found in PXRD patterns of these nanocarbons, suggesting that zirconium species was removed by acid etching. The $I_{\mathrm{G}} / I_{\mathrm{D}}$ ratios (where $I_{\mathrm{G}}$ and $I_{\mathrm{D}}$ represent the G-band $\left(\sim 1,581 \mathrm{~cm}^{-1}\right)$ and D-band $\left(\sim 1,352 \mathrm{~cm}^{-1}\right)$ intensity, respectively), in Fig. 1b, were 0.97, 0.96 and 0.99 for NC-800, INC-800 and BrNC-800, respectively, indicating lots of defects in the nanocarbons, which could provide large amounts of active sites to promote electrocatalysis [61]. Moreover, broad 2D peaks at ca. $2,867 \mathrm{~cm}^{-1}$ further indicated highly graphitized structure in these nanocarbons [62]. The high graphitization degree is beneficial for improving electric conductivity to enhance electrocatalysis activity.

The morphologies of the nanocarbons were investigated by SEM and TEM. As shown in Fig. S5, the resultant porous heteroatom doped nanocarbon materials, NC-800, INC-800 and BrNC-800 retained the shapes of their corresponding parent MOF nanoparticles with very similar sizes between 20 and $30 \mathrm{~nm}$ (Fig. 2 and Fig. S5), which could increase exposed active sites to enhance activity. The HRTEM images (Fig. 2d, Fig. S6) showed that an interplanar space of $0.34 \mathrm{~nm}$ at the edge of three nanocarbon materials indicated the formation of graphic carbon, being in consistence with the XRD results $[9,63]$.

The elemental analysis revealed that the $\mathrm{N}$ contents of NC-800, INC-800 and BrN-C800 were 5.44, 5.03 and 5.12
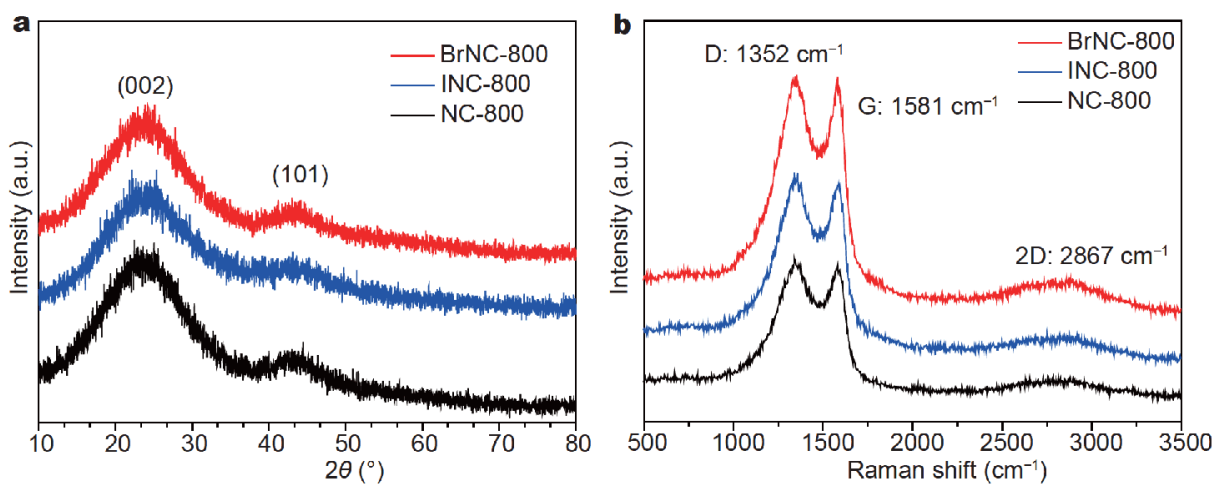

Figure 1 (a) PXRD patterns and (b) Raman spectra of NC-800, INC-800 and BrNC-800. 


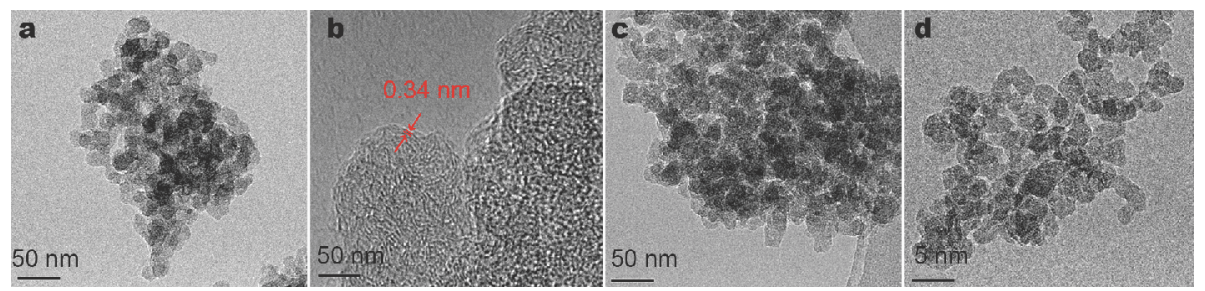

Figure 2 TEM images of (a) NC-800; (b) INC-800 and (c) BrNC-800; (d) HRTEM image of BrNC-800.
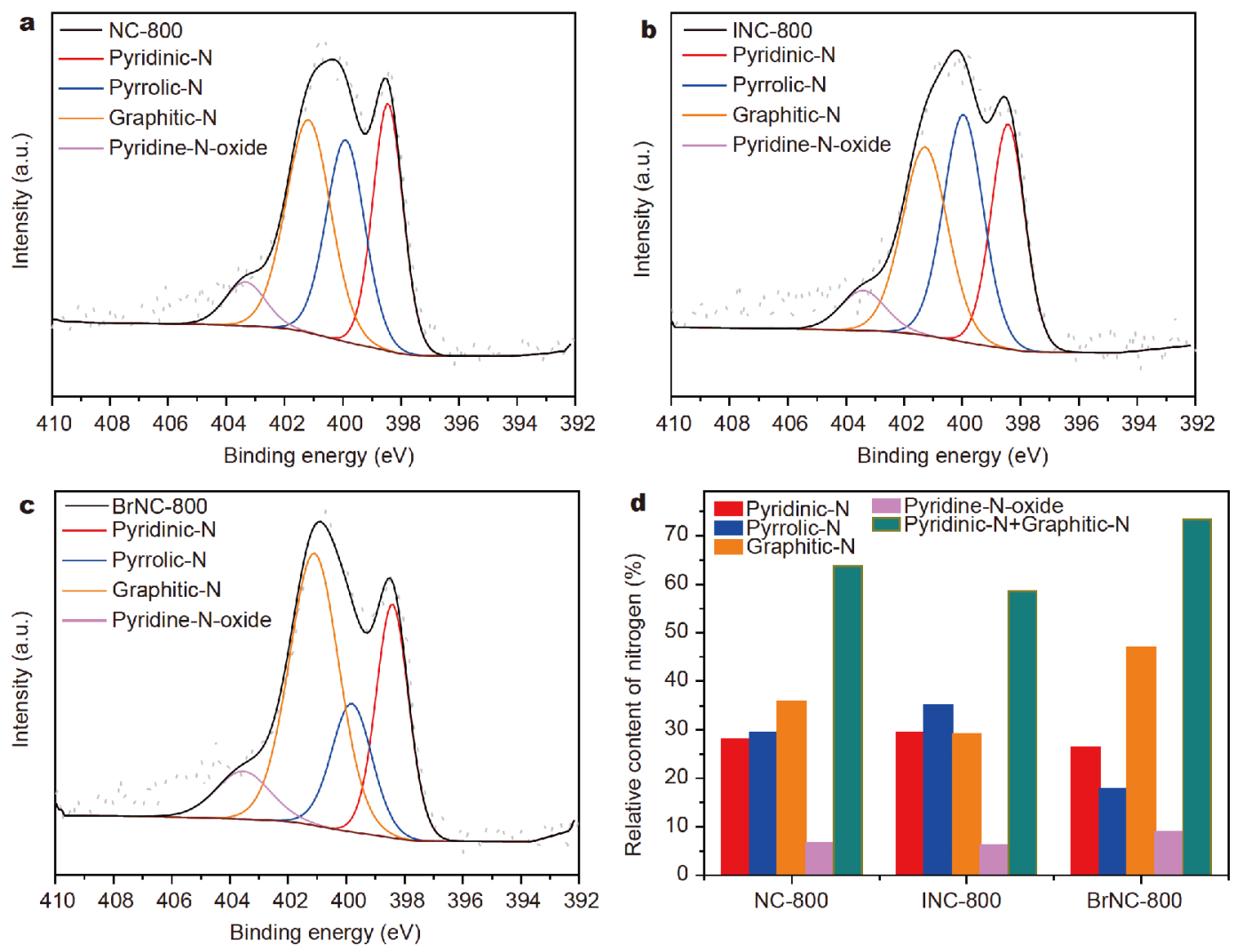

Figure $3 \mathrm{~N}$ 1s spectra of (a) NC-800, (b) INC-800 and (c) BrNC-800. (d) Bar diagrams representing the variation of the four kinds of nitrogen species (pyridinic-N, pyrrolic-N, graphitic-N, and pyridine-N-oxide, respectively) in the various nanocarbons.

wt\%, respectively, which were in accordance with XPS results (Table S2). These results indicated that the highly dispersed $\mathrm{N}$ atoms in MOF precursors have been incorporated into the corresponding nanocarbons. The $\mathrm{N}$ 1s spectra of all the nanocarbons (Fig. 3) were deconvoluted into four different binding energy peaks, pyridinic- $\mathrm{N} \quad(398.3 \pm 0.1 \mathrm{eV})$, pyrrolic-N $(399.8 \pm 0.1 \mathrm{eV})$, graphitic-N $(401.1 \pm 0.1 \mathrm{eV})$ and pyridine-N-oxide (403.3 $\pm 0.2 \mathrm{eV}$ ), respectively [64]. In general, the carbons neighbouring to pyridinic- $\mathrm{N}$ and graphitic- $\mathrm{N}$ species are considered as active sites to promote ORR [65]. As shown in Fig. 3d, graphitic-N species (46.9\%) was dominant in BrNC-800, which has more graphitic-N and pyridinic-N species $(73.3 \%$ in total) than NC-800 (63.8\%) and INC800 (58.6\%), It is estimated that BrNC-800 show higher activity in the electrocatalytic ORR process [23,66-68]. In addition, EDS (Table. S3) revealed that INC-800 and BrNC-800 contained $4.67 \mathrm{wt} \%$ iodine and $0.43 \mathrm{wt} \%$ bromine, respectively. The XPS (Fig. S7) spectrum suggests that both covalent and ionic halogen elements (I or $\mathrm{Br}$ ) have been incorporated into the corresponding nanocarbons [22]. It was deemed that the highest 
electronegativity $(\chi)$ of bromine (2.96) and iodine (2.66) in covalently doped carbon network might impact a relatively high positive charge density on adjacent carbon atoms and thus enhance oxygen reduction activity $[28,29,36]$. In short, XPS analysis of the XNC-800 (X= $\mathrm{Br}, \mathrm{I})$ catalysts revealed the active pyridine- and graphitic$\mathrm{N}$ with active $\mathrm{C}-\mathrm{X}$ bond in the porous nanocarbons.

The nitrogen sorption isotherms of all three nanocarbons have been measured and can be essentially classified as type I, but with relatively high slopes in the $P / P_{0}$ pressure range of $0.85-1.00$ (Fig. 4a). The obvious deviation from an ideal type I isotherm in INC-800 and BrNC-800 indicated that larger pores were formed by the resultant nanocarbons (Fig. 2). The BET surface area for INC-800, NC-800 and BrNC-800 were 633, 902 and $1,165 \mathrm{~m}^{2} \mathrm{~g}^{-1}$, respectively. It should be noted that the hierarchical porous BrNC-800 have a high pore volume of $2.40 \mathrm{~cm}^{3} \mathrm{~g}^{-1}$, which is larger than those of INC-800 $\left(1.65 \mathrm{~cm}^{3} \mathrm{~g}^{-1}\right)$ and $\mathrm{NC}-800\left(0.97 \mathrm{~cm}^{3} \mathrm{~g}^{-1}\right)$. In addition, both of BrNC-800 and INC-800 contained large amounts of mesopores in the range of $2.2-40 \mathrm{~nm}$ (Fig. 4b). The different BET surface area and porous features of resultant nanocarbons may be related to the bulky groups and halogen ions during the carbonization. It is expected that hierarchical porous nanocarbons could expose sufficient active sites and promote mass transfer, leading to high catalytic activity [32,69-71].

LSV curves were tested to the ORR performance of the nanocarbons (Fig. 5a). Among the nanocarbons, BrNC800 shows the highest activity with the most positive onset potential of $0.96 \mathrm{~V}$ ( $v s$. RHE) and half-wave potential of $0.80 \mathrm{~V}$ ( $v s$. RHE), which were comparable to those of the commercial Pt/C (20 wt\%, Alfa Aesar) ( $E_{\text {onset }}=0.95 \mathrm{~V}$ and $E_{1 / 2}=0.81 \mathrm{~V}$, respectively). Moreover, BrNC-800 shows a higher diffusion-limiting current density of $6.00 \mathrm{~mA} \mathrm{~cm}^{-2}$ than the commercial $\mathrm{Pt} / \mathrm{C}$ of $5.16 \mathrm{~mA} \mathrm{~cm}^{-2}$ at $0.2 \mathrm{~V}$ (vs. RHE) under a rotation rate of

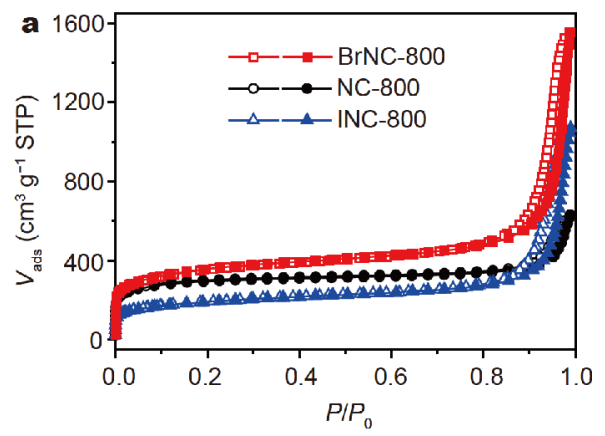

1,600 rpm. The K-L plots for BrNC-800 with approximately parallel fitting lines (Fig. 5b) indicate that the firstorder reaction kinetics of $\mathrm{O}_{2}$ in oxygen reduction reaction is fast, approaching potential-independent electron transfer rate [72]. Furthermore, the high ORR activity of BrNC-800 is further suggested from the low Tafel slope of $84 \mathrm{mV}$ decade ${ }^{-1}$, indicating its fast reaction kinetics (Fig. 5c). RRDE measurements were used to further to confirm its electron transfer number. As shown in Fig. $5 \mathrm{~d}$, the yields of two-electron product $\mathrm{H}_{2} \mathrm{O}_{2}$ by BrNC- 800 are less than $9 \%$ at the potentials from 0.3 to $0.8 \mathrm{~V}$, indicating an efficient four-electron transfer process. The electron transfer numbers $(n)$ for BrNC-800 calculated are 3.82-3.92, which are very close to that of $\mathrm{Pt} / \mathrm{C}$ $(n=3.95)$.

Compared with NC-800, INC-800 and other MOFsderived carbons (Table S4), BrNC-800 exhibited superior ORR catalytic activity most likely due to its high contents of pyridinic-N and graphitic-N species (Fig. 3c). This was in accordance with the previous literatures where the carbons adjacent to pyridinic- $\mathrm{N}$ or graphitic- $\mathrm{N}$ species were the active sites for ORR $[21,65,73,74]$. Secondly, the higher BET surface area and hierarchical porous structure features (Fig. 4) of BrNC-800 could greatly drive the electrolyte to the active sites, thus promoting ORR performance and showing higher diffusion-limited current $[66,75]$. Thirdly, we proposed that the electronegativity of halogen could affect the electronic configuration of active carbon sites in the nanocarbons. BrNC800 showed higher positive onset potential $(0.96 \mathrm{~V})$ than that of NC-800 $(0.89 \mathrm{~V})$ partially because the bromine with higher electronegativity $\left(\chi_{\mathrm{Br}}=2.96\right)$ than carbon (2.55) could polarize the adjacent carbon atoms to activate $\mathrm{O}_{2}$ [21]. The electronegativity of iodine $\left(\chi_{\mathrm{I}}=2.66\right)$ is close to carbon (2.55), and thus INC-800 showed a similar onset potential with that of NC-800. In addition, the higher graphitization in BrNC-800 (Fig. 1b)

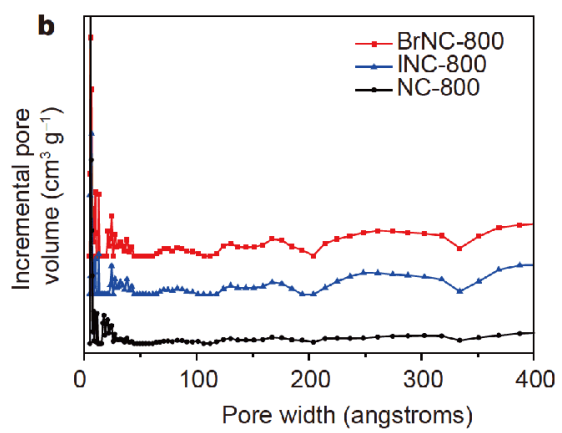

Figure 4 (a) $\mathrm{N}_{2}$ sorption isotherms and (b) pore size distributions for NC-800, INC-800 and BrNC-800. Solid symbols denote adsorption, open symbols denote desorption $\left(P / P_{0}=\right.$ partial pressure $)$. 

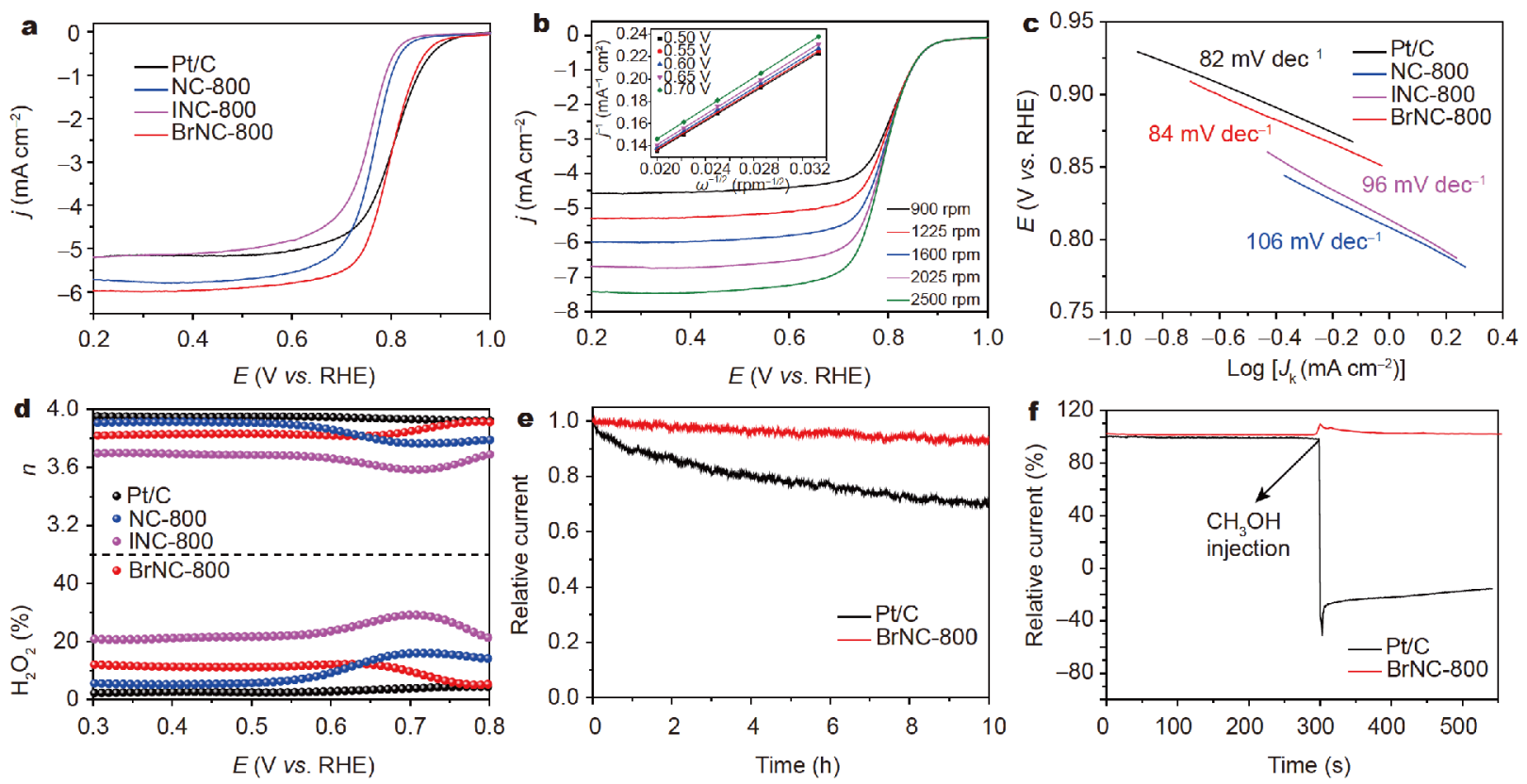

Figure 5 (a) LSV curves for NC-800, INC-800, BrNC-800 and $20 \mathrm{wt} \% \mathrm{Pt} / \mathrm{C}$ at RDE rotation rate of 1,600 rpm with a scan rate of $5 \mathrm{mV} \mathrm{s}{ }^{-1}$ in $\mathrm{O}_{2-}$ saturated $0.1 \mathrm{~mol} \mathrm{~L}^{-1} \mathrm{KOH}$ solution; (b) LSV curves of BrNC-800 at different rotation rates (inset: K-L plots); (c) corresponding Tafel plots obtained from the RDE polarization curves; (d) electron transfer number ( $n$; top) and $\mathrm{H}_{2} \mathrm{O}_{2}$ yield (bottom) by RRDE at 1,600 rpm; (e) current-time chronoamperometry for BrNC-800 and Pt/C in an $\mathrm{O}_{2}$-saturated $0.1 \mathrm{~mol} \mathrm{~L}^{-1} \mathrm{KOH}$ solution; (f) methanol-crossover effects test of $\mathrm{BrNC}-800 \mathrm{and} \mathrm{Pt} / \mathrm{C}$.

was further verified by the electrochemical impedance spectroscopy (EIS) measurement. The Nyquist plots (Fig. S8) revealed that the minimum semicircle of BrNC-800 implied the best conductivity among the three nanocarbons. This high graphitization could accelerate the electron transfer, thus enhancing their electrocatalytic performance.

The stability of electrocatalyst is critical to robust operation in practical applications. The durability of BrNC- 800 and the commercial $\mathrm{Pt} / \mathrm{C}$ was assessed by using current-time chronoamperometry at $0.4 \mathrm{~V}$ in $\mathrm{O}_{2}$ saturated $0.1 \mathrm{~mol} \mathrm{~L}^{-1} \mathrm{KOH}$ (Fig. 5e). After $10 \mathrm{~h}$ of continuous polarization, only $7 \%$ current density loss was observed in BrNC-800, while that of $\mathrm{Pt} / \mathrm{C}$ was $31 \%$, which exemplified the longer durability of BrNC-800. Furthermore, methanol crossover tolerance experiments for BrNC-800 and $\mathrm{Pt} / \mathrm{C}$ were also conducted within and without $1 \mathrm{~mol} \mathrm{~L}^{-1}$ methanol aqueous solution in $\mathrm{O}_{2^{-}}$ saturated $0.1 \mathrm{~mol} \mathrm{~L}^{-1} \mathrm{KOH}$ (Fig. 5f). When methanol was injected, the current of $\mathrm{Pt} / \mathrm{C}$ dropped sharply while that of BrNC-800 remained almost unchanged, demonstrating that BrNC-800 can tolerate methanol.

\section{CONCLUSIONS}

In conclusion, we fabricated porous $\mathrm{N} / \mathrm{halogen}$ dual- doped nanocarbons by using imidazolium-functionalized MOFs as precursors and templates. The $\mathrm{N} / \mathrm{Br}$ dual-doped BrNC-800 exhibited excellent ORR performance with positive onset potential of $0.96 \mathrm{~V}$, which was comparable to the commercial Pt/C. Furthermore, BrNC-800 showed excellent longer-term stability and methanol tolerance. The excellent ORR performance for BrNC-800 might be attributed to the high contents of pyridinic- $\mathrm{N}$ and graphic-N, the synergistic effects of strong electronegative $\mathrm{N} / \mathrm{Br}$ dual-doping and hierarchically porous structure and high surface area. This work provides a facile route from MOFs to fabricate highly efficient and stable heteroatoms-dual-doped carbon electrocatalysts for energy storage and conversion.

\section{Received 28 July 2018; accepted 8 October 2018;} published online 14 November 2018

1 Steele BCH, Heinzel A. Materials for fuel-cell technologies. Nature, 2001, 414: 345-352

2 Dai L, Xue Y, Qu L, et al. Metal-free catalysts for oxygen reduction reaction. Chem Rev, 2015, 115: 4823-4892

3 Stamenkovic VR, Fowler B, Mun BS, et al. Improved oxygen reduction activity on $\mathrm{Pt}_{3} \mathrm{Ni}$ (111) via increased surface site availability. Science, 2007, 315: 493-497

4 Borup R, Meyers J, Pivovar B, et al. Scientific aspects of polymer electrolyte fuel cell durability and degradation. Chem Rev, 2007, 
107: 3904-3951

5 Zhang J, Sasaki K, Sutter E, et al. Stabilization of platinum oxygenreduction electrocatalysts using gold clusters. Science, 2007, 315 : 220-222

6 Zhang $\mathrm{C}$, Sandorf W, Peng Z. Octahedral $\mathrm{Pt}_{2} \mathrm{CuNi}$ uniform alloy nanoparticle catalyst with high activity and promising stability for oxygen reduction reaction. ACS Catal, 2015, 5: 2296-2300

7 Huang X, Zhao Z, Cao L, et al. High-performance transition metaldoped $\mathrm{Pt}_{3} \mathrm{Ni}$ octahedra for oxygen reduction reaction. Science, 2015, 348: 1230-1234

8 Kuroki H, Tamaki T, Matsumoto $\mathrm{M}$, et al. Refined structural analysis of connected platinum-iron nanoparticle catalysts with enhanced oxygen reduction activity. ACS Appl Energy Mater, 2018, 1: 324-330

9 Wu G, More KL, Johnston CM, et al. High-performance electrocatalysts for oxygen reduction derived from polyaniline, iron, and cobalt. Science, 2011, 332: 443-447

10 Byon HR, Suntivich J, Shao-Horn Y. Graphene-based non-noblemetal catalysts for oxygen reduction reaction in acid. Chem Mater, 2011, 23: 3421-3428

11 Lefèvre M, Proietti E, Jaouen F, et al. Iron-based catalysts with improved oxygen reduction activity in polymer electrolyte fuel cells. Science, 2009, 324: 71-74

12 Wang DW, Su D. Heterogeneous nanocarbon materials for oxygen reduction reaction. Energy Environ Sci, 2014, 7: 576-591

13 Liang Y, Li Y, Wang $\mathrm{H}$, et al. $\mathrm{Co}_{3} \mathrm{O}_{4}$ nanocrystals on graphene as a synergistic catalyst for oxygen reduction reaction. Nat Mater, 2011, 10: $780-786$

14 Zhang $\mathrm{H}$, Zhou $\mathrm{W}$, Chen $\mathrm{T}$, et al. A modular strategy for decorating isolated cobalt atoms into multichannel carbon matrix for electrocatalytic oxygen reduction. Energy Environ Sci, 2018, 11: 1980-1984

15 Zeng L, Cui X, Shi J. A facile strategy for ultrasmall Pt NPs being partially-embedded in $\mathrm{N}$-doped carbon nanosheet structure for efficient electrocatalysis. Sci China Mater, 2018, 61: 1557-1566

16 Tan H, Li Y, Jiang X, et al. Perfectly ordered mesoporous ironnitrogen doped carbon as highly efficient catalyst for oxygen reduction reaction in both alkaline and acidic electrolytes. Nano Energy, 2017, 36: 286-294

$17 \mathrm{Wu}$ S, Zhu Y, Huo Y, et al. Bimetallic organic frameworks derived $\mathrm{CuNi} /$ carbon nanocomposites as efficient electrocatalysts for oxygen reduction reaction. Sci China Mater, 2017, 60: 654-663

$18 \mathrm{Bu} \mathrm{L}$, Zhang N, Guo S, et al. Biaxially strained $\mathrm{PtPb} / \mathrm{Pt}$ core/shell nanoplate boosts oxygen reduction catalysis. Science, 2016, 354: 1410-1414

$19 \mathrm{Bu} \mathrm{L}$, Shao Q, E B, et al. PtPb/PtNi intermetallic core/atomic layer shell octahedra for efficient oxygen reduction electrocatalysis. J Am Chem Soc, 2017, 139: 9576-9582

20 Bu L, Tang C, Shao Q, et al. Three-dimensional $\mathrm{Pd}_{3} \mathrm{~Pb}$ nanosheet assemblies: high-performance non-Pt electrocatalysts for bifunctional fuel cell reactions. ACS Catal, 2018, 8: 4569-4575

21 Gong K, Du F, Xia Z, et al. Nitrogen-doped carbon nanotube arrays with high electrocatalytic activity for oxygen reduction. Science, 2009, 323: 760-764

22 Liu R, Wu D, Feng X, et al. Nitrogen-doped ordered mesoporous graphitic arrays with high electrocatalytic activity for oxygen reduction. Angew Chem, 2010, 122: 2619-2623

23 Sheng $\mathrm{ZH}$, Shao L, Chen JJ, et al. Catalyst-free synthesis of nitrogen-doped graphene via thermal annealing graphite oxide with melamine and its excellent electrocatalysis. ACS Nano, 2011,
5: 4350-4358

24 Yang L, Jiang S, Zhao Y, et al. Boron-doped carbon nanotubes as metal-free electrocatalysts for the oxygen reduction reaction. Angew Chem, 2011, 123: 7270-7273

25 Sheng ZH, Gao HL, Bao WJ, et al. Synthesis of boron doped graphene for oxygen reduction reaction in fuel cells. J Mater Chem, 2012, 22: 390-395

26 Liu ZW, Peng F, Wang HJ, et al. Phosphorus-doped graphite layers with high electrocatalytic activity for the $\mathrm{O}_{2}$ reduction in an alkaline medium. Angew Chem, 2011, 123: 3315-3319

27 Yang Z, Yao Z, Li G, et al. Sulfur-doped graphene as an efficient metal-free cathode catalyst for oxygen reduction. ACS Nano, 2012, 6: 205-211

28 Yao Z, Nie H, Yang Z, et al. Catalyst-free synthesis of iodine-doped graphene via a facile thermal annealing process and its use for electrocatalytic oxygen reduction in an alkaline medium. Chem Commun, 2012, 48: 1027-1029

29 Jeon IY, Choi HJ, Choi M, et al. Facile, scalable synthesis of edgehalogenated graphene nanoplatelets as efficient metal-free eletrocatalysts for oxygen reduction reaction. Sci Rep, 2013, 3: 1810

30 Zhang M, Dai L. Carbon nanomaterials as metal-free catalysts in next generation fuel cells. Nano Energy, 2012, 1: 514-517

31 You C, Jiang X, Wang X, et al. Nitrogen, sulfur co-doped carbon derived from naphthalene-based covalent organic framework as an efficient catalyst for oxygen reduction. ACS Appl Energy Mater, 2018, 1: 161-166

32 Liang J, Jiao Y, Jaroniec M, et al. Sulfur and nitrogen dual-doped mesoporous graphene electrocatalyst for oxygen reduction with synergistically enhanced performance. Angew Chem Int Ed, 2012, 51: 11496-11500

33 Guo Z, Jiang C, Teng C, et al. Sulfur, trace nitrogen and iron codoped hierarchically porous carbon foams as synergistic catalysts for oxygen reduction reaction. ACS Appl Mater Interfaces, 2014, 6: 21454-21460

34 Li J, Chen Y, Tang Y, et al. Metal-organic framework templated nitrogen and sulfur co-doped porous carbons as highly efficient metal-free electrocatalysts for oxygen reduction reactions. J Mater Chem A, 2014, 2: 6316-6319

35 Yan D, Guo L, Xie C, et al. N, P-dual doped carbon with trace Co and rich edge sites as highly efficient electrocatalyst for oxygen reduction reaction. Sci China Mater, 2018, 61: 679-685

36 Jiang S, Sun Y, Dai H, et al. Nitrogen and fluorine dual-doped mesoporous graphene: a high-performance metal-free ORR electrocatalyst with a super-low $\mathrm{HO}_{2}{ }^{-}$yield. Nanoscale, 2015, 7: 10584-10589

37 Peera SG, Sahu AK, Arunchander A, et al. Nitrogen and fluorine co-doped graphite nanofibers as high durable oxygen reduction catalyst in acidic media for polymer electrolyte fuel cells. Carbon, 2015, 93: 130-142

38 Paraknowitsch JP, Thomas A. Doping carbons beyond nitrogen: an overview of advanced heteroatom doped carbons with boron, sulphur and phosphorus for energy applications. Energy Environ Sci, 2013, 6: 2839-2855

39 Yang $\mathrm{Z}$, Nie $\mathrm{H}$, Chen $\mathrm{X}$, et al. Recent progress in doped carbon nanomaterials as effective cathode catalysts for fuel cell oxygen reduction reaction. J Power Sources, 2013, 236: 238-249

40 Ranjbar Sahraie N, Paraknowitsch JP, Göbel C, et al. Noble-metalfree electrocatalysts with enhanced ORR performance by taskspecific functionalization of carbon using ionic liquid precursor systems. J Am Chem Soc, 2014, 136: 14486-14497 
41 Fellinger TP, Su DS, Engenhorst M, et al. Thermolytic synthesis of graphitic boron carbon nitride from an ionic liquid precursor: mechanism, structure analysis and electronic properties. J Mater Chem, 2012, 22: 23996-24005

42 Fulvio PF, Lee JS, Mayes RT, et al. Boron and nitrogen-rich carbons from ionic liquid precursors with tailorable surface properties. Phys Chem Chem Phys, 2011, 13: 13486-13491

43 Lee JS, Wang X, Luo $\mathrm{H}$, et al. Facile ionothermal synthesis of microporous and mesoporous carbons from task specific ionic liquids. J Am Chem Soc, 2009, 131: 4596-4597

44 Mahmood A, Guo W, Tabassum $\mathrm{H}$, et al. Metal-organic framework-based nanomaterials for electrocatalysis. Adv Energy Mater, 2016, 6: 1600423

45 Dang S, Zhu QL, Xu Q. Nanomaterials derived from metal-organic frameworks. Nat Rev Mater, 2017, 3: 17075

46 Liu B, Shioyama H, Akita T, et al. Metal-organic framework as a template for porous carbon synthesis. J Am Chem Soc, 2008, 130: 5390-5391

47 Jiang HL, Liu B, Lan YQ, et al. From metal-organic framework to nanoporous carbon: toward a very high surface area and hydrogen uptake. J Am Chem Soc, 2011, 133: 11854-11857

48 Aijaz A, Akita T, Yang H, et al. From ionic-liquid@metal-organic framework composites to heteroatom-decorated large-surface area carbons: superior $\mathrm{CO}_{2}$ and $\mathrm{H}_{2}$ uptake. Chem Commun, 2014, 50: 6498-6501

49 Jiang HL, Xu Q. Porous metal-organic frameworks as platforms for functional applications. Chem Commun, 2011, 47: 3351-3370

$50 \mathrm{Hu} \mathrm{M}$, Reboul J, Furukawa S, et al. Direct carbonization of Albased porous coordination polymer for synthesis of nanoporous carbon. J Am Chem Soc, 2012, 134: 2864-2867

51 Yi FY, Zhang R, Wang $\mathrm{H}$, et al. Metal-organic frameworks and their composites: synthesis and electrochemical applications. Small Methods, 2017, 1: 1700187

52 Lin T, Chen IW, Liu F, et al. Nitrogen-doped mesoporous carbon of extraordinary capacitance for electrochemical energy storage. Science, 2015, 350: 1508-1513

53 Meng J, Niu C, Xu L, et al. General oriented formation of carbon nanotubes from metal-organic frameworks. J Am Chem Soc, 2017, 139: 8212-8221

54 Zhao S, Yin H, Du L, et al. Carbonized nanoscale metal-organic frameworks as high performance electrocatalyst for oxygen reduction reaction. ACS Nano, 2014, 8: 12660-12668

55 Tang H, Yin H, Wang J, et al. Molecular architecture of cobalt porphyrin multilayers on reduced graphene oxide sheets for highperformance oxygen reduction reaction. Angew Chem, 2013, 125: 5695-5699

56 Xia W, Zou R, An L, et al. A metal-organic framework route to in situ encapsulation of $\mathrm{Co} @ \mathrm{Co}_{3} \mathrm{O}_{4} @ \mathrm{C}$ core@bishell nanoparticles into a highly ordered porous carbon matrix for oxygen reduction. Energy Environ Sci, 2015, 8: 568-576

57 Lu XF, Gu LF, Wang JW, et al. Bimetal-organic framework derived $\mathrm{CoFe}_{2} \mathrm{O}_{4} / \mathrm{C}$ porous hybrid nanorod arrays as high-performance electrocatalysts for oxygen evolution reaction. Adv Mater, 2017, 29: 1604437

58 Liang J, Chen RP, Wang XY, et al. Postsynthetic ionization of an imidazole-containing metal-organic framework for the cycloaddition of carbon dioxide and epoxides. Chem Sci, 2017, 8: 1570-1575

59 Pachfule P, Biswal BP, Banerjee R. Control of porosity by using isoreticular zeolitic imidazolate frameworks (IRZIFs) as a template for porous carbon synthesis. Chem Eur J, 2012, 18: 11399-11408
60 Zhao X, Zou X, Yan X, et al. Defect-driven oxygen reduction reaction (ORR) of carbon without any element doping. Inorg Chem Front, 2016, 3: 417-421

61 Zhu Y, Murali S, Cai W, et al. Graphene and graphene oxide: synthesis, properties, and applications. Adv Mater, 2010, 22: 39063924

62 Zhang L, Wang X, Wang R, et al. Structural evolution from metalorganic framework to hybrids of nitrogen-doped porous carbon and carbon nanotubes for enhanced oxygen reduction activity. Chem Mater, 2015, 27: 7610-7618

63 Zheng J, Ekström TC, Gordeev SK, et al. Carbon with an onionlike structure obtained by chlorinating titanium carbide. J Mater Chem, 2000, 10: 1039-1041

64 Kundu S, Nagaiah TC, Xia W, et al. Electrocatalytic activity and stability of nitrogen-containing carbon nanotubes in the oxygen reduction reaction. J Phys Chem C, 2009, 113: 14302-14310

65 Guo D, Shibuya R, Akiba C, et al. Active sites of nitrogen-doped carbon materials for oxygen reduction reaction clarified using model catalysts. Science, 2016, 351: 361-365

66 Guan BY, Yu L, (David) Lou XW. A dual-metal-organicframework derived electrocatalyst for oxygen reduction. Energy Environ Sci, 2016, 9: 3092-3096

67 Vikkisk M, Kruusenberg I, Joost U, et al. Electrocatalytic oxygen reduction on nitrogen-doped graphene in alkaline media. Appl Catal B-Environ, 2014, 147: 369-376

68 Zhang G, Luo H, Li H, et al. ZnO-promoted dechlorination for hierarchically nanoporous carbon as superior oxygen reduction electrocatalyst. Nano Energy, 2016, 26: 241-247

69 Chang H, Joo SH, Pak C. Synthesis and characterization of mesoporous carbon for fuel cell applications. J Mater Chem, 2007, 17: $3078-3088$

70 Liang J, Du X, Gibson C, et al. N-doped graphene natively grown on hierarchical ordered porous carbon for enhanced oxygen reduction. Adv Mater, 2013, 25: 6226-6231

71 Shi PC, Yi JD, Liu TT, et al. Hierarchically porous nitrogen-doped carbon nanotubes derived from core-shell ZnO@zeolitic imidazolate framework nanorods for highly efficient oxygen reduction reactions. J Mater Chem A, 2017, 5: 12322-12329

72 Zhang L, Su Z, Jiang F, et al. Highly graphitized nitrogen-doped porous carbon nanopolyhedra derived from ZIF-8 nanocrystals as efficient electrocatalysts for oxygen reduction reactions. Nanoscale, 2014, 6: 6590-6602

73 Lai L, Potts JR, Zhan D, et al. Exploration of the active center structure of nitrogen-doped graphene-based catalysts for oxygen reduction reaction. Energy Environ Sci, 2012, 5: 7936-7942

74 Bao Z, Chang G, Xing H, et al. Potential of microporous metalorganic frameworks for separation of hydrocarbon mixtures. Energy Environ Sci, 2016, 9: 3612-3641

75 Zheng F, Yang Y, Chen Q. High lithium anodic performance of highly nitrogen-doped porous carbon prepared from a metalorganic framework. Nat Commun, 2014, 5: 5261

Acknowledgements We acknowledge the financial support from the National Key Research and Development Program of China (2018YFA0208600), National Basic Research Program of China (973 Program, 2014CB845605), Key Research Program of Frontier Science, Chinese Academy of Sciences (QYZDJ-SSW-SLH045), Strategic Priority Research Program of the Chinese Academy of Sciences (XDB20000000), National Natural Science Foundation of China (21671188, 21871263, 21521061 and 21331006) and Youth Innovation Promotion Association, 
Chinese Academy of Sciences (2014265).

Author contributions Huang $\mathrm{YB}$ and $\mathrm{Wu} \mathrm{Q}$ designed and engineered the samples; Wu Q, Liang J, Yi JD, Shi PC performed the experiments and the characterizations. $\mathrm{Wu} Q$ wrote the paper with support from Huang YB and Cao R. All authors contributed to the general discussion.
Conflict of interest The authors declare no conflict of interest.

Supplementary information Supplementary data are available in the online version of the paper.
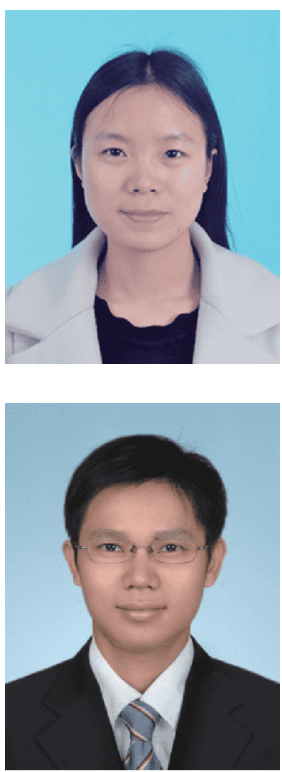

Qiao Wu received her bachelor's degree from the School of Chemistry and Chemical Engineering, Henan Normal University in 2016. She is currently a master candidate in the College of Chemistry and Materials Science, Fujian Normal University, Fuzhou, China. Her current research interest focuses on designing high-performance electrode materials for energy storage systems.

Yuan-Biao Huang obtained his PhD in 2009 under the supervision of Prof. GX Jin from Fudan University. In the same year, he joined Prof. Rong Cao's group at Fujian Institute of Research on the Structure of Matter (FJIRSM), Chinese Academy of Sciences (CAS). In 2014, he joined Prof. Qiang Xu's group at the National Institute of Advanced Industrial Science and Technology as a JSPS (Japan Society for the Promotion of Science) fellow. In 2015, he moved back to Prof. Cao's research group at FJIRSM. His research interest focuses on porous MOF and COF based materials for catalysis.

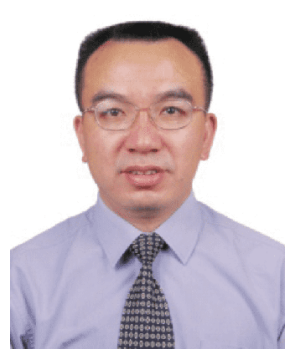

Rong Cao was born in Fujian province, China. He obtained his PhD from FJIRSM, CAS, in 1993. Following post-doctoral experience in the Hong Kong Polytechnic University and JSPS Fellowship in Nagoya University, he became a professor at FJIRSM in 1998. Now, he is the director of FJIRSM. His main research interest includes supramolecular chemistry, inorganic-organic hybrid materials and nanocatalysis.

\section{咪唑鍮盐官能化阳离子型金属-有机框架衍生的多孔氮/卤素双掺杂纳米碳高效氧还原催化剂}

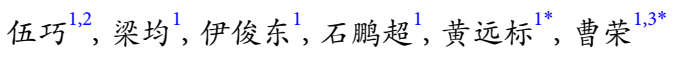

摘要 低成本、高效稳定的非金属材料作为氧还原反应 $(\mathrm{ORR})$ 的电催化剂对于燃料电池的规模化应用至关重要. 杂原子掺杂的多孔碳材 料具有可调的化学组成和电子结构, 能显著提升氧还原催化活性. 基于此, 我们采用咪唑鈆盐功能化的金属-有机框架(MOFs)作为前驱体 和自牺牲模板, 制备了氮和卤素双掺杂多孔纳米碳催化剂. 其中氮/澳双掺杂催化剂BrNC-800在碱性条件下具有优异的电催化性能、稳定 性和抗甲醇毒化能力. 其优异的电催化活性归因于: (1) 大量吡啶氮和石墨氮的掺杂产生丰富的碳活性位点, 同时高的石墨化程度有助于 提高导电性, 促进氧还原活性; (2) 澳的存在改变了催化剂的化学组分和结构特征, 并活化相邻碳产生额外活性位点; (3) 高比表面和多级 孔结构有助于传质与增加暴露的氧还原活性位的数量, 而提高催化效率. 这项工作为以MOFs为前驱体制备高效的杂原子双掺杂碳材料提 供了一种简便的方法. 